Original Article

\title{
An explanatory model of functional exercise capacity in patients with systemic sclerosis: considerations for rehabilitation programs
}

Agnaldo José Lopes, $\mathrm{PhD}^{1)^{*}}$, Arthur de Sá Ferreira, $\mathrm{PhD}^{1)}$,

Tatiana Rafaela Lemos Lima, MSc ${ }^{1)}$, Sara Lucia Silveira Menezes, PhD $^{1)}$, Fernando Silva Guimarães, $\mathrm{PhD}^{1)}$

1) Rehabilitation Sciences Post-Graduation Program, Augusto Motta University Center: Rua Araguaia, 1266, bloco 1/405, Freguesia, Jacarepaguá, 22745-271, Rio de Janeiro, RJ, Brazil

\begin{abstract}
Purpose] This study aimed to evaluate the impact of lung function and peripheral muscle function on the six-minute walking distance (6MWD) in systemic sclerosis (SS) patients and, thereby, to develop an explanatory model of functional exercise capacity for these individuals. [Methods] In a cross-sectional study, $31 \mathrm{SS}$ patients underwent pulmonary function testing (including spirometry, diffusing capacity for carbon monoxide [DLCO], and respiratory muscle strength), isometric dynamometry with surface electromyography, and the 6MWD. [Results] There was a significant correlation between the 6MWD (\% predicted, 6MWD\%) and the following parameters: height $(r=0.427)$ and DLCO $(r=0.404)$. In contrast, no other independent variable showed a significant correlation with the $6 \mathrm{MWD} \%(\mathrm{r} \leq 0.257)$. The final prediction model for $6 \mathrm{MWD} \%$ (adjusted $\mathrm{R}^{2}=0.456$, SE of bias $=12 \%$ ) was $6 \mathrm{MWD} \%_{\text {Gibbons }}=-131.3+1.16 \times$ height $_{\mathrm{cm}}+0.33 \times \mathrm{DLCO}_{\% \text { predicted. }}$ [Conclusion] In SS patients, body height and pulmonary diffusion are the main determinants of the $6 \mathrm{MWD}$. Our results justify further investigation of the performance of SS patients during exercise, which may increase the understanding of the pathophysiological mechanisms involved in the disease. The impact of these findings in SS patients may be useful for evaluating the effects of rehabilitation programs.

Key words: Scleroderma, Respiratory function tests, Exercise
\end{abstract}

(This article was submitted Sep. 30, 2015, and was accepted Nov. 17, 2015)

\section{INTRODUCTION}

Systemic sclerosis (SS) is a connective tissue disease characterized by the activation of fibroblasts and abnormal accumulation of extracellular matrix, leading to severe multisystemic effects, many of which are debilitating ${ }^{1)}$. SS is a rare disease with an overall incidence ranging from $0.3-2.8$ cases per 100,000 per year and an estimated prevalence of 10 cases per 100,000 people $^{2,3)}$. The disease affects women in more than $80 \%$ of cases $^{3)}$. The constant changes arising from chronic SS affect the whole body. The progression of SS is characterized by involvement of the respiratory, cardiovascular, muscular and osteoarticular systems, leading to a significant impact on patient functionality ${ }^{4}$.

Pulmonary involvement is currently the leading cause of death in SS. The lungs are affected in 70-90\% of SS patients, with interstitial lung disease and pulmonary arterial hypertension being the most frequent pulmonary complications ${ }^{5)}$. Excess collagen irreversibly damages lung structures, alveolar walls, and interstitial spaces, altering respiratory mechanics, pulmonary ventilation, and gas exchange, resulting in restrictive ventilatory dysfunction. As symptoms progress, dyspnea with mild exertion appears ${ }^{6}$.

The prevalence of muscular involvement in SS varies between 7-81\%, which reflects the high degree of heterogeneity in

*Corresponding author. Agnaldo José Lopes (E-mail: phel.lop@uol.com.br)

(C2016 The Society of Physical Therapy Science. Published by IPEC Inc.

This is an open-access article distributed under the terms of the Creative Commons Attribution Non-Commercial No Derivatives (by-nc-nd) License $<$ http://creativecommons.org/licenses/by-nc-nd/4.0/>. 
the defining criteria used ${ }^{7,8)}$. Some drugs may affect SS muscle disease, because muscle weakness develops in conjunction with therapeutic use of agents known to cause myopathy ${ }^{9}$. Osteoarticular complications have also been described, occurring in up to $70 \%$ of patients with $\mathrm{SS}^{10)}$. The lesions are usually located near the joints, causing atrophy due to disuse, joint contractures, and muscle shortening ${ }^{11)}$.

A reduced six-minute walking distance (6MWD) predicts an increased risk of morbidity and mortality in several patient populations ${ }^{12,13)}$. In SS, the six-minute walk test (6MWT) has been used increasingly to monitor and track the disease ${ }^{14)}$. Due to the vasculopathies that occur in SS, blood flow to the lungs and heart becomes inadequate, which, in conjunction with musculoskeletal complications, limits exercise capacity ${ }^{15}$ ). Despite the importance of the $6 \mathrm{MWT}$ in several clinical conditions, its value has often been questioned in SS patients, due to weak correlations with clinical parameters and the absence of objective assessments of the impact of peripheral dysfunction on the $6 \mathrm{MWD}^{16,17)}$.

The 6MWT is considered of great value for identifying possible risk factors in different diseases ${ }^{18,19)}$. Although many factors can potentially influence exercise performance in patients with SS, few studies have addressed their role during physical activity in these individuals. We hypothesized that the various limitations occurring in SS cause different effects on 6MWT performance. Thus, our objective was to evaluate the impact of lung function and peripheral muscle function on exercise performance in patients with SS and thereby develop an explanatory model of functional exercise capacity for these individuals.

\section{SUBJECTS AND METHODS}

This study used a cross-sectional design, including 31 patients with SS, and was conducted between September 2013 and July 2014. These patients were regularly seen at the Federal Hospital of Bonsucesso and at the Federal Hospital of Lagoa in Rio de Janeiro, Brazil. The diagnosis of SS was confirmed following the recommendations of the American College of Rheumatology/European League against Rheumatism ${ }^{20)}$.

The inclusion criteria encompassed men and women with SS $\geq 18$ years of age. The exclusion criteria were history of smoking or asthma, presence of neurological diseases, presence of orthopedic disorders or a history of orthopedic surgery, and presence of any physical disability that would render the individuals unable to perform the 6MWT. All patients signed an informed consent form, which was previously approved by the Research Ethics Committee of the Augusto Motta University Center under study number 300.826/2013.

All measurements were taken within two days. Pulmonary function tests, isometric dynamometry, and surface electromyography were performed on the first day, while the 6MWT was administered on the second day.

The pulmonary function testing consisted of spirometry, diffusing capacity for carbon monoxide (DLCO), and respiratory muscle strength tests ${ }^{21-23)}$. Spirometry was performed with the KoKo PFT spirometer (PDS Instrumentation, Inc., Louisville, CO, USA). DLCO and respiratory muscle strength tests were performed using the HDpft 3000 device (nSpire Health, Inc., Longmont, CO, USA). All assessments followed the protocol established by the American Thoracic Society/European Respiratory Society ${ }^{24)}$. The pulmonary function testing results were expressed as the percent of the predicted values ${ }^{25-27)}$.

Peripheral muscle strength was assessed by isometric dynamometry (model DIN-TRO, EMG System do Brasil LTDA, Brazil), and the endurance test was performed adding surface electromyography (EMG model 810C, EMG System do Brasil LTDA, Brazil). Maximal voluntary isometric contractions (MVIC) were performed at 90 degrees of knee flexion ${ }^{28)}$. The patient underwent three MVIC with a 2-minute interval between them, and the highest value was selected. The endurance test consisted of a sustained contraction for 60 seconds, using $30 \%$ of the MVIC values. The median frequency and root mean square slopes (MDF slope and RMS slope, respectively), corresponding to the EMG signal during isometric contraction over time, were used to represent the fatigue tolerance of the patients. The MDF slope is associated with the firing rates of motor units, while the RMS slope measures electrical activity during contraction ${ }^{29}$ ).

The 6MWT was performed in a 30-m-long corridor ${ }^{30,31)}$. The heart rate, peripheral oxygen saturation, and degree of dyspnea were measured before, in the third minute, and at the end of the test, following the American Thoracic Society recommendations ${ }^{13)}$. Heart rate was monitored with a Polar FT1 exercise tracker (Polar, Inc., Kempele, Finland). Oxygen saturation was measured by finger pulse oximetry using a Masimo Radical SET pulse oximeter (Masimo, Inc., Irvine, CA, USA). The degree of dyspnea was assessed by the modified Borg scale. The tests were repeated twice, and the highest value was recorded $\left.{ }^{13}, 32,33\right)$. The predicted values were calculated by equations of Gibbons et al. ${ }^{34)}$ that were previously used in patients with $\mathrm{SS}^{11,35)}$. The equations developed by Gibbons et al. provide a set of reference values for healthy individuals in a wide age range ${ }^{34)}$.

Several models were tested with variables commonly used as predictors of 6MWD (\% predicted, 6MWD\%). Anthropometric data variables (age, weight, height, and body mass index [BMI]) were entered into the model. Results from the assessment of pulmonary function (forced vital capacity [FVC], maximal inspiratory pressure [MIP], maximal expiratory pressure [MEP], and DLCO, all in \%predicted values), peripheral muscular strength (MVIC), and fatigue (RMS slope and MDF slope), were also entered into the model. A forward stepwise method was applied, using the adjusted $\mathrm{R}^{2}$ value as a criterion for entry $(p<0.05)$ and removal $(p>0.10)$ of variables.

The overall performance measures of the regression consisted of the $\mathrm{R}^{2}$ value adjusted for the number of variables retained in the proposed model, as well as the standard error of the difference (bias = measured - predicted). The specific performance 
of the new prediction model was assessed by regression diagnosis and calibration analyses as described below ${ }^{36)}$.

Regression diagnosis was performed using Pearson's correlation coefficient between the dependent and independent variables and among the independent ones. Multicollinearity was assessed using the variance inflation factor (VIF); a VIF > 5 indicates that the associated regression coefficients are poorly estimated ${ }^{37}$. Analysis of residuals was also performed using empirical distributions of residuals ${ }^{38}$, and the one-sample Kolmogorov-Smirnov test was used with the Lilliefors correction to test the null hypothesis of normality of the distribution of residuals.

Calibration was verified by an assessment of the calibration plot (measured vs. predicted, along with regression lines showing slope and intercept) and the limits of agreement (LOA) plot. The bias was tested against 0 with the one sample Student's t-test. The error was determined as the SD of the bias. The LOA plot ${ }^{39}$ ) was used to determine bias and agreement between the values predicted by the equations and those measured. LOA were defined as the upper and lower 95\% CI and were determined by the mean differences $\pm 1.96 \mathrm{SD}$.

A complete-case analysis was conducted because there were no missing data. Data were initially tabulated in Excel (Microsoft Corporation, USA), and statistical analysis was performed using SPSS 22 (IBM Corp., USA). Descriptive results are shown as the mean \pm SD and frequency (\%) for continuous and categorical variables, respectively. Predicted values were calculated using the simplified model using coefficients rounded to three digits of precision. Statistical significance was considered as $\mathrm{p}<0.05$ (two-tailed) for all analyses.

\section{RESULTS}

A total of 55 outpatients were initially selected for inclusion in the study. Thirty-one of these met the inclusion criteria, while 24 were excluded for the following reasons: history of smoking $(n=9)$, refusal to participate in the study $(n=4)$, physical disability impairing locomotion $(n=4)$, oxygen desaturation at rest $(n=3)$, asthma $(n=2)$, and history of orthopedic surgery $(n=2)$. Thus, the final study population included 29 women and 2 men, with a mean age of $47.5 \pm 14.0$ years. The mean duration of illness was $7.14 \pm 5.60$ years. Eighteen patients exhibited the diffuse form of the disease, and 13 exhibited the limited form. The mean distance covered was $461.9 \pm 101.4$ meters. Table 1 shows the demographic, clinical, pulmonary function, peripheral muscle performance, and functional capacity data of the studied sample.

The $6 \mathrm{MWD} \%$ was significantly correlated with body height $(\mathrm{r}=0.427, \mathrm{p}=0.017)$ and $\mathrm{DLCO}_{\%}$ predicted $(\mathrm{r}=0.404, \mathrm{p}=0.024)$. No other independent variable showed a significant correlation with the $6 \mathrm{MWD} \%(\mathrm{r} \leq 0.257, \mathrm{p} \geq 0.162$; Table 2$)$.

Significant associations among the independent variables included the paired analyses of the following: weight and BMI $(\mathrm{r}=0.908 ; \mathrm{p}<0.001)$; RMS slope and MDF slope $(\mathrm{r}=0.845 ; \mathrm{p}<0.001) ; \mathrm{FVC}_{\%}$ predicted with $\mathrm{DLCO}_{\%}$ predicted $(\mathrm{r}=0.652 ; \mathrm{p}<0.001)$; age $(\mathrm{r}=0.402 ; \mathrm{p}=0.025)$ and $\mathrm{MEP}_{\% \text { predicted }}(\mathrm{r}=0.357 ; \mathrm{p}=0.049)$; and $\mathrm{MEP}_{\% \text { predicted }}$ with $\mathrm{MIP}_{\% \text { predicted }}(\mathrm{r}=0.609 ; \mathrm{p}<0.001)$ and $\mathrm{DLCO}_{\% \text { predicted }}(\mathrm{r}=0.396 ; \mathrm{p}=0.027)$. Multicollinearity was not identified for any independent variable (height $=1.063, \mathrm{DLCO}_{\%}$ predict $=1.063$ ).

The adjusted $\mathrm{R}^{2}$ values obtained using the stepwise method began at 0.154 , including height as the first variable. Entering the variable $\mathrm{DLCO}_{\%}$ predicted significantly increased the adjusted $\mathrm{R}^{2}$ values to 0.456 . The forward inclusion of all other independent variables did not significantly increase the adjusted $\mathrm{R}^{2}$ value. The final prediction model for $6 \mathrm{MWD} \%$ (equation 1 ; adjusted $\mathrm{R}^{2}=0.456, \mathrm{SE}$ of bias $=12 \%, \mathrm{p}<0.001$ ) was as follows (Table 3 ):

$$
\text { (1) } 6 \mathrm{MWD}_{\% \text { Gibbons }}=-131.284+1.161 \times \text { height }_{\mathrm{cm}}+0.330 \times \mathrm{DLCO}_{\% \text { predicted }}
$$

There was an obvious relationship between the bias and the mean; the bias SD was $0.1 \pm 11.3 \%$. The histogram plot of the differences showed no apparent skew, and the assumption of normality of the distribution was not violated $(\mathrm{p}=0.200)$. The $95 \%$ CI for the bias was $[-4 ; 4] \%$, and the LOA and respective 95\% CI for the lower and upper LOA were $-22 \%$ [ -29 ; $-15]$ and $22 \%$ [15; 29], respectively.

\section{DISCUSSION}

The 6MWT is a simple submaximal test that does not require expensive equipment and is highly reproducible; furthermore, it reflects quality of life and the ability to perform activities of daily living, and has been used to evaluate various patient populations ${ }^{13}$. In the present study, the mean 6MWD value was close to those observed by Deuschle et al. ${ }^{40)}$, Garin et al. ${ }^{41)}$, and Schoindre et al. ${ }^{17}$, who also evaluated SS patients. However, these authors only measured the absolute value of the 6MWD and did not consider predictive equations, rendering it difficult to accurately compare the results ${ }^{17,40,41)}$. The non-use of reference equations is important because the demographic data independently affect the 6MWD in healthy adults, requiring additional interpretation of test results when these confounding factors are not used ${ }^{13)}$.

In our study, the DLCO was the only pulmonary function test parameter that was included in the explanatory model for the 6MWD. Corroborating our findings, the DLCO (\% predicted) was also an explanatory variable for the 6MWD in Deuschle et $\mathrm{al}^{40)}$ and Garin et $\mathrm{al}^{41)}$. Interestingly, a declining DLCO in patients with SS is the single most significant marker of poor outcome $^{42)}$. In SS, Peters-Golden et al. ${ }^{43)}$ showed a 5 year cumulative survival rate of only $9 \%$ in patients with DLCO $\leq 40 \%$, compared with $75 \%$ when the DLCO was $>40 \%$. The distance for pulmonary diffusion includes the entire route from the 
alveolar gas to the hemoglobin in the red blood cell. In SS, a decreased DLCO may represent both a structural change in the alveolar-capillary membrane as well as a change in the capillary blood volume because both interstitial fibrosis and pulmonary hypertension are common complications of this disease ${ }^{44)}$. It should be mentioned that FVC and DLCO are the lung function parameters currently most often used in monitoring patients with $\mathrm{SS}^{6}$.

Table 1. Demographic data, lung function, peripheral muscle performance, and functional capacity of patients with systemic sclerosis

\begin{tabular}{|c|c|}
\hline Variable & Value \\
\hline \multicolumn{2}{|l|}{ Demographic data } \\
\hline Age (years) & $47.5 \pm 14.0$ \\
\hline Weight $(\mathrm{kg})$ & $60.6 \pm 13.2$ \\
\hline Height $(\mathrm{cm})$ & $156.9 \pm 7.48$ \\
\hline $\operatorname{BMI}\left(\mathrm{kg} / \mathrm{m}^{2}\right)$ & $24.6 \pm 5.24$ \\
\hline \multicolumn{2}{|l|}{ Clinical data } \\
\hline Raynaud's phenomenon & $30(96.8)$ \\
\hline Arthralgia & $21(67.7)$ \\
\hline Interstitial lung disease & $15(48.4)$ \\
\hline Gastrointestinal disease & $10(32.2)$ \\
\hline Cardiovascular disease & $8(25.8)$ \\
\hline \multicolumn{2}{|l|}{ Previous or current treatment } \\
\hline Glucocorticoids & $17(54.8)$ \\
\hline Chloroquine & $11(35.5)$ \\
\hline Methotrexate & $8(25.8)$ \\
\hline Cyclophosphamide & $7(22.6)$ \\
\hline Calcium-channel blockers & $7(22.6)$ \\
\hline Bosentan & $5(16.1)$ \\
\hline Epoprostenol & $4(12.9)$ \\
\hline \multicolumn{2}{|l|}{ Lung function } \\
\hline FVC (\% predict) & $75.1 \pm 19.6$ \\
\hline DLCO (\% predict $)$ & $63.0 \pm 24.6$ \\
\hline MIP (\% predict) & $56.0 \pm 17.7$ \\
\hline MEP (\% predict) & $43.0 \pm 14.2$ \\
\hline \multicolumn{2}{|l|}{ Peripheral muscle performance } \\
\hline MVIC (kg) & $26.8 \pm 8.81$ \\
\hline RMS slope & $0.87 \pm 0.37$ \\
\hline MDF slope & $-0.20 \pm 8.21$ \\
\hline 6MWD (\% predict) & $71.4 \pm 15.3$ \\
\hline
\end{tabular}

Results are presented as the mean \pm SD.

BMI: body mass index; FVC: forced vital capacity; DLCO: diffusing capacity for carbon monoxide; MIP: maximal inspiratory pressure; MEP: maximal expiratory pressure; MVIC: maximal voluntary isometric contractions; RMS slope: median frequency slope; MDF slope: root mean square slope; 6MWD: 6-minute walking distance
Table 2. Correlation analysis of the six-minute walking distance as predicted by Gibbons et al. (2001) and independent variables used in the model

\begin{tabular}{lc}
\hline Independent variables & $\begin{array}{c}\text { Pearson's correlation coefficient } \\
\text { (dependent: 6MWD) } \\
\text { (\% predicted) }\end{array}$ \\
\hline Height $(\mathrm{cm})$ & $0.427^{*}$ \\
DLCO $(\%$ predict) & $0.404^{*}$ \\
MVIC $(\mathrm{kg})$ & $0.257(\mathrm{p}=0.162)$ \\
MEP $(\%$ predict) & $0.255(\mathrm{p}=0.167)$ \\
FVC $(\%$ predict $)$ & $0.243(\mathrm{p}=0.187)$ \\
MIP $(\%$ predict $)$ & $0.207(\mathrm{p}=0.265)$ \\
Weight $(\mathrm{kg})$ & $0.165(\mathrm{p}=0.375)$ \\
RMS slope $(\mathrm{V} / \mathrm{s})$ & $-0.151(\mathrm{p}=0.451)$ \\
MDF slope $(\mathrm{V} / \mathrm{s})$ & $0.094(\mathrm{p}=0.640)$ \\
Age $($ years $)$ & $-0.018(\mathrm{p}=0.925)$ \\
BMI $\left(\mathrm{kg} / \mathrm{m}^{2}\right)$ & $0.003(\mathrm{p}=0.998)$ \\
\hline
\end{tabular}

6MWD: 6-minute walking distance; DLCO: diffusing capacity for carbon monoxide; MVIC: maximal voluntary isometric contraction; MEP: maximal expiratory pressure; FVC: forced vital capacity; MIP: maximal inspiratory pressure; RMS slope: median frequency slope; MDF slope: root mean square slope; BMI: body mass index. *p<0.05

Table 3. Multivariate regression analysis for prediction of six-minute walking distance in patients with systemic sclerosis

\begin{tabular}{lccc}
\hline Model & Coefficient [95\% CI] & Std. Error & $\mathrm{t}$ \\
\hline Intercept & $-131.284[-230.687 ;-31.882]$ & 48.527 & $-2.705^{*}$ \\
Height $(\mathrm{cm})$ & $1.161[0.549 ; 1.772]$ & 0.299 & $3.887^{* *}$ \\
DLCO $(\%$ predict $)$ & $0.330[0.150 ; 0.510]$ & 0.088 & $3.755^{* *}$ \\
\hline
\end{tabular}

DLCO: diffusing capacity for carbon monoxide. $* \mathrm{p}<0.05 ; * \mathrm{p}<0.01$ 
In our study, height was also included in the explanatory model for 6MWD. This finding is not surprising, because the $6 \mathrm{MWD}$ is directly related to height in multiple predictive equations ${ }^{25,45}$. Intuitively, a greater height is associated with a larger step, which most likely results in a greater distance covered by taller individuals ${ }^{13)}$. Compared with healthy individuals, it is possible that the frequency of steps interferes further in the 6MWD of patients with SS, because osteoarticular involvement is observed in $46-97 \%$ of patients with $\mathrm{SS}^{11,46)}$.

Muscle weakness is a common occurrence in patients with $\mathrm{SS}^{8)}$. In the present study, however, we did not observe any relationship between peripheral muscle function (strength or endurance) and 6MWD. Since severe pulmonary involvement with reduced DLCO is a common finding in patients with SS, we speculate that the limitation on exercise tolerance by deteriorating gas exchange imposes an additional limitation to that caused by peripheral muscle dysfunction. Thus, these patients could complete the 6MWT with an important change in gas exchange, but still with reasonable performance of the lower limbs muscles. We believe the cardiopulmonary exercise testing (CPET) could better demonstrate the limitation caused by peripheral muscle dysfunction, since the $6 \mathrm{MWT}$ is a submaximal test. In fact, an association between peak oxygen uptake measured by CPET and peripheral muscle dysfunction has been demonstrated by some authors ${ }^{47)}$.

The strength of the present study is that it provides an explanatory model for functional exercise capacity in patients with SS based on predictive 6MWD equations, after eliminating various confounding factors. Furthermore, we considered the influence of the peripheral muscle strength measured objectively in this model. The need for a study using the impact of this measurement on the interpretation of the 6MWT had previously been stated by several authors ${ }^{43,44)}$. However, this study has specific limitations that should be considered. First, gender was not considered in the correlation analysis because the disease affects women in almost $90 \%$ of cases ${ }^{48)}$; in fact, in the present study there were 29 women and only two men. Moreover, most of the variables were analyzed with respect to the predicted percentage; this allowed the standardization of absolute values for gender, including the value of DLCO that came into the final prediction model. Second, we did not investigate pulmonary vasculopathy or left ventricular dysfunction that may have influenced the patient's performance on the $6 \mathrm{MWT}^{14,15)}$.

In conclusion, the results show that, in patients with SS, body height and pulmonary diffusion are the main determinants of the 6MWD. We believe it is important to validate this predictive model in another scleroderma population. Moreover, we believe that our results justify further investigation of the performance of patients with SS during exercise.

\section{ACKNOWLEDGEMENT}

This research was supported by the Rio de Janeiro State Research Supporting Foundation (FAPERJ).

\section{REFERENCES}

1) Delisle VC, Kwakkenbos L, Hudson M, et al. Canadian Scleroderma Research Group: An assessment of the measurement equivalence of English and French versions of the Center for Epidemiologic Studies Depression (CES-D) Scale in systemic sclerosis. PLoS ONE, 2014, 9: e102897. [Medline] [CrossRef]

2) Sticherling M: Systemic sclerosis-dermatological aspects. Part 1: Pathogenesis, epidemiology, clinical findings. J Dtsch Dermatol Ges, 2012, 10: 705-718, quiz 716. [Medline]

3) Strollo D, Goldin J: Imaging lung disease in systemic sclerosis. Curr Rheumatol Rep, 2010, 12: 156-161. [Medline] [CrossRef]

4) Hunzelmann N: [Systemic scleroderma]. Hautarzt, 2013, 64: 299-310, quiz 311-312. [Medline] [CrossRef]

5) Gohari Moghadam K, Gharibdoost F, Parastandechehr G, et al.: Assessments of pulmonary involvement in patients with systemic sclerosis. Arch Iran Med, 2011, 14: 22-26. [Medline]

6) Solomon JJ, Olson AL, Fischer A, et al.: Scleroderma lung disease. Eur Respir Rev, 2013, 22: 6-19. [Medline] [CrossRef]

7) Medsger TA Jr, Rodnan GP, Moossy J, et al.: Skeletal muscle involvement in progressive systemic sclerosis (scleroderma). Arthritis Rheum, 1968, 11: 554-568. [Medline] [CrossRef]

8) Clements PJ, Furst DE, Campion DS, et al.: Muscle disease in progressive systemic sclerosis: diagnostic and therapeutic considerations. Arthritis Rheum, 1978, 21: 62-71. [Medline] [CrossRef]

9) Estes ML, Ewing-Wilson D, Chou SM, et al.: Chloroquine neuromyotoxicity. Clinical and pathologic perspective. Am J Med, 1987, 82: 447-455. [Medline] [CrossRef]

10) Ranque B, Bérezné A, Le-Guern V, et al.: Myopathies related to systemic sclerosis: a case-control study of associated clinical and immunological features. Scand J Rheumatol, 2010, 39: 498-505. [Medline] [CrossRef]

11) Lima TR, Guimarães FS, Silva LA, et al.: Relationship between functional capacity, joint mobility and pulmonary 
function in patients with systemic sclerosis. J Bodyw Mov Ther, 2015, 19: 17-24. [Medline] [CrossRef]

12) Ciolac EG, Guimarães GV: Physical exercise and metabolic syndrome. Rev Bras Med Esporte, 2004, 10: 319-324.

13) ATS Committee on Proficiency Standards for Clinical Pulmonary Function Laboratories: ATS statement: guidelines for the six-minute walk test. Am J Respir Crit Care Med, 2002, 166: 111-117. [Medline] [CrossRef]

14) Walkey AJ, Ieong M, Alikhan M, et al.: Cardiopulmonary exercise testing with right-heart catheterization in patients with systemic sclerosis. J Rheumatol, 2010, 37: 1871-1877. [Medline] [CrossRef]

15) Rosato E, Romaniello A, Magrì D, et al.: Exercise tolerance in systemic sclerosis patients without pulmonary impairment: correlation with clinical variables. Clin Exp Rheumatol, 2014, 32: S-103-S-108. [Medline]

16) Holland AE, Goh NS: The six-minute walk test in scleroderma: what should we measure and how should we measure it? Respirology, 2012, 17: 588-589. [Medline] [CrossRef]

17) Schoindre Y, Meune C, Dinh-Xuan AT, et al.: Lack of specificity of the 6-minute walk test as an outcome measure for patients with systemic sclerosis. J Rheumatol, 2009, 36: 1481-1485. [Medline] [CrossRef]

18) Peungsuwan P, Sermcheep P, Harnmontree P, et al.: The effectiveness of Thai exercise with traditional massage on the pain, walking ability and QOL of older people with knee osteoarthritis: a randomized controlled trial in the community. J Phys Ther Sci, 2014, 26: 139-144. [Medline] [CrossRef]

19) Bang DH, Shin WS, Noh HJ, et al.: Effect of unstable surface training on walking ability in stroke patients. J Phys Ther Sci, 2014, 26: 1689-1691. [Medline] [CrossRef]

20) van den Hoogen F, Khanna D, Fransen J, et al.: 2013 classification criteria for systemic sclerosis: an American College of Rheumatology/European League against Rheumatism collaborative initiative. Arthritis Rheum, 2013, 65: $2737-$ 2747. [Medline] [CrossRef]

21) Roh HL: Changes in respiratory function following intermittent living in the upland environment and the lowland environment. J Phys Ther Sci, 2014, 26: 335-339. [Medline] [CrossRef]

22) Lopes AJ, Pinto Almeida V, Silveira Menezes SL, et al.: Balance deficits are correlated with bronchial obstruction markers in subjects with asthma. J Phys Ther Sci, 2014, 26: 393-399. [Medline] [CrossRef]

23) Seo K, Cho M: The effects on the pulmonary function of normal adults proprioceptive neuromuscular facilitation respiration pattern exercise. J Phys Ther Sci, 2014, 26: 1579-1582. [Medline] [CrossRef]

24) Miller MR, Hankinson J, Brusasco V, et al. ATS/ERS Task Force: Standardisation of spirometry. Eur Respir J, 2005, 26: 319-338. [Medline] [CrossRef]

25) Pereira CA, Sato T, Rodrigues SC: New reference values for forced spirometry in white adults in Brazil. J Bras Pneumol, 2007, 33: 397-406. [Medline] [CrossRef]

26) Neder JA, Andreoni S, Lerario MC, et al.: Reference values for lung function tests. II. Maximal respiratory pressures and voluntary ventilation. Braz J Med Biol Res, 1999, 32: 719-727. [Medline]

27) Neder JA, Andreoni S, Peres C, et al.: Reference values for lung function tests. III. Carbon monoxide diffusing capacity (transfer factor). Braz J Med Biol Res, 1999, 32: 729-737. [Medline] [CrossRef]

28) Ohsugi H, Murata S, Kubo A, et al.: Verification of the correlation between cognitive function and lower limb muscle strength for the community-dwelling elderly. J Phys Ther Sci, 2014, 26: 1861-1863. [Medline] [CrossRef]

29) Guedes da Silva DP, Guimarães FS, Dias CM, et al.: On the functional capacity and quality of life of patients with acromegaly: are they candidates for rehabilitation programs? J Phys Ther Sci, 2013, 25: 1497-1501. [Medline] [CrossRef]

30) Yağci N, Duymaz T, Cavlak U: How does pain localization affect physical functioning, emotional status and independency in older adults with chronic musculoskeletal pain? J Phys Ther Sci, 2014, 26: 1189-1192. [Medline] [CrossRef]

31) Horie J, Ito K, Hayashi S, et al.: The usefulness of the incremental load repeated standup test in the assessment of the exercise capacity of patients with chronic obstructive pulmonary disease. J Phys Ther Sci, 2013, 25: 391-395. [CrossRef]

32) Dias FM, Costa SO, Pereira de Freitas J, et al.: Functional capacity of oldest old living in a long-stay institution in Rio de Janeiro, Brazil. J Phys Ther Sci, 2014, 26: 1097-1105. [Medline] [CrossRef]

33) Park I, Lee Y, Moon B, et al.: A comparison of the effects of overground gait training and treadmill gait training according to stroke patients' gait velocity. J Phys Ther Sci, 2013, 25: 379-382. [CrossRef]

34) Gibbons WJ, Fruchter N, Sloan S, et al.: Reference values for a multiple repetition 6-minute walk test in healthy adults older than 20 years. J Cardiopulm Rehabil, 2001, 21: 87-93. [Medline] [CrossRef]

35) Lima TR, Guimarães FS, Carvalho MN, et al.: Lower limb muscle strength is associated with functional performance 
and quality of life in patients with systemic sclerosis. Braz J Phys Ther, 2015, 19: 129-136. [Medline] [CrossRef]

36) Collins GS, de Groot JA, Dutton S, et al.: External validation of multivariable prediction models: a systematic review of methodological conduct and reporting. BMC Med Res Methodol, 2014, 14: 40. [Medline] [CrossRef]

37) Marquardt DW: Generalized inverse, ridge regression, biased linear estimation, and nonlinear estimation. Technometrics, 1970, 12: 591-612. [CrossRef]

38) Toutenburg H: Statistical analysis of designed experiments, 2nd ed. New York: Springer, 2002.

39) Bland JM, Altman DG: Statistical methods for assessing agreement between two methods of clinical measurement. Int J Nurs Stud, 2010, 47: 931-936. [CrossRef]

40) Deuschle K, Weinert K, Becker MO, et al.: Six-minute walk distance as a marker for disability and complaints in patients with systemic sclerosis. Clin Exp Rheumatol, 2011, 29: S53-S59. [Medline]

41) Garin MC, Highland KB, Silver RM, et al.: Limitations to the 6-minute walk test in interstitial lung disease and pulmonary hypertension in scleroderma. J Rheumatol, 2009, 36: 330-336. [Medline] [CrossRef]

42) Nihtyanova SI, Schreiber BE, Ong VH, et al.: Prediction of pulmonary complications and long-term survival in systemic sclerosis. Arthritis Rheum (Munch), 2014, 66: 1625-1635. [Medline] [CrossRef]

43) Peters-Golden M, Wise RA, Hochberg MC, et al.: Carbon monoxide diffusing capacity as predictor of outcome in systemic sclerosis. Am J Med, 1984, 77: 1027-1034. [Medline] [CrossRef]

44) Alhamad EH, Lynch JP 3rd, Martinez FJ: Pulmonary function tests in interstitial lung disease: what role do they have? Clin Chest Med, 2001, 22: 715-750, ix. [Medline] [CrossRef]

45) Chetta A, Zanini A, Pisi G, et al.: Reference values for the 6-min walk test in healthy subjects 20-50 years old. Respir Med, 2006, 100: 1573-1578. [Medline] [CrossRef]

46) Baron M, Lee P, Keystone EC: The articular manifestations of progressive systemic sclerosis (scleroderma). Ann Rheum Dis, 1982, 41: 147-152. [Medline] [CrossRef]

47) Blom-Bülow B, Jonson B, Bauer K: Factors limiting exercise performance in progressive systemic sclerosis. Semin Arthritis Rheum, 1983, 13: 174-181. [Medline] [CrossRef]

48) Galluccio F, Walker UA, Nihtyanova S, et al.: Registries in systemic sclerosis: a worldwide experience. Rheumatology (Oxford), 2011, 50: 60-68. [Medline] [CrossRef] 